Ana Laura Goñi Fitipaldo*, Norma Piazza**, Marcelo Payssé Alvarez ${ }^{* * *}$, Hugo Inda****

\title{
El paisaje como mediador de nuevas pedagogías y tecnologías ${ }^{1}$
}

\author{
New pedagogies and technologies through \\ the landscape recognition \\ Cómo citar:
}

Goñi Fitipaldo, A., Piazza, N., Payssé, M., \& Inda, H. (2019). El paisaje como mediador de nuevas pedagogías y tecnologías. Designia, 6 (2), 25-53.

${ }^{1}$ Este artículo se deriva de la investigación FSED-2-2016-1-130781, la cual fue financiada por la Agencia Nacional de Investigación e Innovación (ANII) y la Fundación Conectividad Educativa de Informática Básica para el Aprendizaje en Línea (Ceibal) de Uruguay, en el marco de la Convocatoria 2016 del Fondo Sectorial de Educación (FSED). Adicionalmente, en el ámbito del proyecto "La Ciudad Inteligente: un palimpsesto digital", financiado por la Comisión Sectorial de Investigación Científica de la Universidad de la República se realizaron las aproximaciones tecnológicas del

\section{Pallabras clave:}

Paisaje, pedagogía, tecnología

\section{Key words:}

Landscape, pedagogy, technology.

Recibido: 29/08/2018

Aceptado: 01/11/2018

*Arquitecta, 1997, Universidad de la República (UDELAR), Uruguay. Magister en Diseño del Paisaje, 2015, Universidad Pontificia Bolivariana (UPB) Medellín, Colombia. Doctoranda en Arquitectura desde 2016. Profesora Adjunta de la Facultad de Arquitectura, Diseño y Urbanismo (FADU) en la Licenciatura en Diseño de Paisaje. Investigadora en el Departamento de Territorio, Ambiente y Paisaje en el Centro Universitario Regional del Este (CURE), Uruguay. E-mail: analauragoni@gmail.com ORCID: 0000-0002-8025-9172

**Arquitecta, 1998 (UDELAR, Uruguay), Magister en Diseño del Paisaje, 2015 (UPB, Medellín, Colombia), Doctoranda en Arquitectura desde 2016. Investigadora del Instituto de Diseño, Programa

Paisaje y Espacio público de FADU. Profesora Adjunta de la Licenciatura en Diseño de Paisaje y del Diploma de Especialización en Proyecto de Paisaje. Integrante del Departamento de Territorio,

Ambiente y Paisaje en el CURE. Integrante de LALI (Iniciativa Latinoamericana del Paisaje). E-mail: normapiazzac@gmail.com ORCID: 0000-0003-1196-8175 
***Arquitecto, 1981 (UDELAR, Uruguay). Especialización en educación a distancia, 2004 (Universidad Federal de Pelotas, Brasil). Profesor Titular de FADU, UDELAR. Director del Departamento de Informática Aplicada al Diseño. Especialista en Realidad Virtual, Realidad Aumentada, Fabricación Digital. E-mail: paysse@fadu.edu.uy ORCID: 0000-0002-7895-3026

\footnotetext{
**** Licenciado en Ciencias Antropológicas (Arqueología), Magister y Doctor en Ciencias (Ecología). Se desempeña como docente en el CURE, UDELAR, Uruguay. Es investigador del Sistema Nacional de Investigación, del área Geociencias del Programa de Desarrollo de las Ciencias Básicas (PEDECIBA) y de diversos programas de posgrado del Uruguay. A nivel de grado desarrolla actividad de docencia en la Licenciatura en Gestión Ambiental del CURE. E-mail: hinda@cure.edu.uy ORCID: 0000-0003-1955-7821
}

\section{Resumen:}

La investigación presentada en este artículo se desarrolló en un lapso de doce meses y tuvo como marco procesos de enseñanza-aprendizaje en etapa escolar que consideran al paisaje como espacio estimulador del aprendizaje y vehículo para la aplicación de nuevas herramientas pedagógicas. Participaron educandos y educadores de la escuela rural 88 "Faro José Ignacio" (Uruguay), quienes indagaron y profundizaron en la percepción del paisaje local. El acercamiento al área se propuso a través de herramientas tecnológicas de visualización remota para establecer distintos parámetros, tales como vínculos entre escala y detalle, recorridos cotidianos y apreciación de ecosistemas locales. La incidencia de incorporar estos recursos fue evaluada mediante el análisis de dibujos y relatos realizados por los niños y la comparación de cartografías de paisaje previas y posteriores a su uso. Los resultados se volcaron en formato comunicacional y de contenidos adecuado a la población escolar. El producto final, elaborado de forma participativa, fue la plataforma digital Paisajes Pedagógicos (http://www.plapp.edu.uy), la cual presenta siete puntos de observación con capacidad de visión 360 grados y puntos sensibles que despliegan información adicional (fichas de aves, fichas de vegetales, cambios temporales en la morfología costera). Las visuales pueden ocupar toda la pantalla, ofrecen ayudas para la navegación y posibilidades de orbitar, cambiar de ubicación, agrandar y capturar la imagen, a través de menús auxiliares. Por su diseño metodológico, este proceso-producto es replicable y, como tal, se pretende extender la experiencia a futuro con nuevos proyectos en otras escuelas del país. 
Research this paper deals with was conducted within twelve months as part of teaching-learning processes at school which consider the landscape as a stimulating space for learning and a vehicle for the application of new pedagogical tools. Students and teachers from the rural school 88 "Faro José Ignacio" (Uruguay) worked together to explore and deepen the perception of their local environment, which was approached through remote visualization technological tools in order to set different parameters, such as links between scale and detail, daily routes and appreciation of local ecosystems. The incidence of incorporating these resources was evaluated by analysing drawings and stories made by the children and comparing landscape cartographies both before and after their use. The results were turned into communicational content that is suitable for the school population. Thus, the digital platform Paisajes Pedagógicos (Pedagogical Landscapes, http://www.plapp. edu.uy) was constructed in a participative way as the final product. It features seven 360-degree vision observation points and buttons displaying additional information (vegetable and bird records, temporal changes in coastal morphology). The views can cover the entire screen while navigation help is offered as well as options to rotate, change location, maximize and capture the images thanks to auxiliary menus. Because of its methodological design, this process-product is replicable which is why the experience is intended to be extended with new projects in other schools of the country.

INTRODUCCIÓN

La educación sobre el paisaje contiene varias vertientes: se trata de educar en el paisaje (conociéndolo), para el paisaje (asumiendo responsabilidades), pero también por medio del paisaje, utilizándolo como instrumento en un proceso de crecimiento general tanto del individuo como de la comunidad. (Castiglioni, 2011, p.387).

En el ámbito internacional existen antecedentes de investigaciones y trabajos acerca del paisaje como mediador de nuevas pedagogías en la infancia. En Europa, a partir del Convenio Europeo del Paisaje del año 2000, los países se comprometieron a fomentar una formación específica, desde la etapa escolar hasta la universitaria, para tratar los valores asociados al paisaje y las cuestiones relativas a su protección, 
gestión y planificación (Nogué, 2011). En América del Norte, también en el cambio de milenio, comenzaron a aparecer publicaciones académicas que revalorizan y rescatan el potencial transformador del paisaje, al ofrecer nuevas reflexiones disciplinares (Corner, 1999). En Latinoamérica, a partir de la Iniciativa Latinoamericana del Paisaje (LALI), firmada en 2012 en Medellín (Colombia) durante el Congreso de la International Federation of Landscape Architects (IFLA), empieza a desarrollarse una concientización hacia la necesidad de la educación en paisaje como proceso bottom-up.

El paisaje es hoy un constructo cultural, multidimensional y complejo. El paisaje no es un mero lugar físico sino el conjunto de una serie de ideas, sensaciones y sentimientos que elaboramos a partir del lugar y sus elementos constituyentes (Maderuelo, 2005). Además, pone en juego cierto sentido del espacio que es preciso sacar a la luz (Besse, 2010). Por ende, educar en paisaje no solo significa promoverlo sino preparar a la sociedad para su intervención sustentable.

Las relaciones entre paisaje y percepción fueron estudiadas en profundidad en las décadas de los sesenta y los setenta del siglo XX. Autores como Anne Whyte, Amos Rapoport y Kevin Lynch hicieron valiosos aportes en este sentido. Según este último: "profundizar nuestra percepción del medio ambiente equivaldría a prolongar un dilatado desarrollo biológico y cultural que ha ido desde los sentidos de contacto a los sentidos de distancia, y desde los sentidos de distancia ha pasado a la comunicación simbólica" (Lynch, 1960, p. 23).

La Percepción Ambiental (Environmental Perception) aparece como un campo multidisciplinario con algunos problemas investigativos en común. En oposición a un medio ambiente único con características inmutables, introduce la noción de variabilidad cultural. Además, difiere de la percepción de los objetos en la escala, la textura, las secuencias de movimientos y la adición de panorámicas (Rapoport, 1978). Los mapas mentales, un elemento clave en la Percepción Ambiental, son transformaciones psicológicas a través de las cuales los seres humanos adquieren, codifican, recuerdan y decodifican información de su medio ambiente espacial, es decir, las distancias relativas, direcciones y combinación de elementos. Este sistema es muy primario, pues también existe en los animales, y se apoya en la locomoción, la experiencia y la orientación espacial. A través de procesos de mapificación, las personas identifican dominios espaciales, definen su lugar en ellos, se orientan en 
y se mueven a través de los lugares. Estos mapas se relacionan con el concepto de imaginabilidad de Lynch (1960): “la cualidad de un objeto físico que le da una gran probabilidad de suscitar una imagen vigorosa en cualquier observador de que se trate." (p. 19). De esta forma, se elaboran imágenes mentales del medio ambiente.

Asimismo, hay antecedentes de estudios asociados con la percepción ambiental y la del paisaje vinculadas a la edad física de las personas y, en particular, de la niñez. En esta etapa, el paisaje tiene un rol fundamental en la estructuración del sentido del lugar, en la identidad y en las relaciones afectivas del niño con el espacio que habita. La educación en paisaje desde las primeras etapas de la vida reconoce los vínculos perceptivos inevitablemente establecidos con el entorno y la interdependencia con la sociedad (Busquets, 2011). Cabe mencionar que el concepto de topophilia ha sido acuñado para explorar las dimensiones humanísticas y fenomenológicas del paisaje (Tuan, 1990).

Respecto a los drones en la educación, experiencias anuales se han realizado en Uruguay en el día de la Ciencia y la Tecnología en diferentes liceos y escuelas de la ciudad de Montevideo. En el ámbito internacional existen publicaciones que dan cuenta del empleo de estos recursos con fines educativos (Carnahan,Crowley\&Zieger, 2016; Kakaes, 2015). Es preciso reconocer que el niño contemporáneo, quien navega a través de Google Earth, posee una percepción visual del paisaje terrestre radicalmente distinta a la de aquel de siglos anteriores. Así, la idea general de paisaje como construcción cultural se ve unida a la sensación de disfrute en la apreciación de la imagen de un territorio (Goñi, 2012). 
En relación al aprendizaje profundo hay tres elementos clave a considerar: el primero es la creación de nuevo conocimiento y el uso de aquel presente en el mundo a partir de la utilización de tecnologías; el segundo es el cambio del foco en la educación: dirigir la focalización de los contenidos hacia el proceso de aprendizaje; por último, los estudiantes han de contar con actitud proactiva, capacidad para ser actores de su propio aprendizaje y habilidad para responder a cambios y desafíos (Fullan\&Langworthy, 2014). En las actividades efectuadas en el proyecto con los niños de la escuela 88, las cartografías de paisaje fueron un desafío a construir. Las representaciones cartográficas se convirtieron en un medio para aprender a aprender, un reto en sí mismo a explorar (Sala, 2013).

El estímulo a la creatividad es uno de los objetivos de las nuevas pedagogías. En este sentido, las descripciones útiles a la pedagogía de la creatividad tienen en cuenta las interacciones y los efectos del contexto, dada la heterogeneidad de los espacios culturales que son las instituciones educativas y las aulas, sin aferrarse a una ilusoria homogeneidad de verdades inamovibles (Fandiño, 2008).

La relación pedagógica aparece cuando existe una experiencia de encuentro de subjetividades y diversos saberes. De tal forma, enseñar y aprender no es solo planificar una secuencia de contenidos o evaluar determinadas competencias adquiridas, sino que implica centrar la atención en cómo se posibilitan esos encuentros en que se comparten subjetividades y saberes (Hernández, 2011).

El proyecto aquí presentado generó, en la vida interna de la escuela 88, acontecimientos con características particulares -rápidos,efímeros,múltiples- propios de la contemporaneidad, de acuerdo con la definición de los seis temas claves del actual milenio expuesta por Italo Calvino. La multiplicidad está vinculada con el actual modo de conocimiento por el cual el mundo se interpreta como una compleja trama de relaciones sobrepuestas, una intrincada red de conexiones (Calvino, 1999). Dicha trama implica movimientos externos e internos, una relocalización de los roles del docente y el alumno para pensar desde otro lugar y generar nuevos vínculos en el espacio escolar cotidiano. 
La noción de paisaje no es única sino múltiple y se construye por el cuerpo sociocultural de una sociedad. Para los efectos de este trabajo se comprende el paisaje como construcción cultural y perceptiva en la cual sujetos, poblaciones o individuos encuentran y dan sentido a una parte del territorio. Tal visión encuentra consonancia con lo planteado por Folch y Bru (2017): “El paisaje refleja la realidad ambiental de cada lugar, al tiempo que compendia la historia del proceso antrópico que en él se haya podido desarrollar. De ahí que el concepto paisaje sea en realidad un algoritmo socioecológico."(p.55).

La revisión bibliográfica y de antecedentes para la investigación se concentró en tres temáticas en paralelo: el paisaje en la infancia, el aprendizaje profundo y los drones en la educación. Así, el marco de trabajo estuvo definido por los procesos de enseñanza-aprendizaje en etapa escolar que consideran al paisaje como mediador de nuevas pedagogías y espacio estimulador del aprendizaje, mientras que el acercamiento al territorio se propuso a través de nuevos dispositivos tecnológicos, entendidos como instrumentos para aprender a aprender y herramientas para visualizar y descubrir paisajes.

El derrotero de investigación-acción planteó como base operativa piloto la escuela rural 88, "Faro José Ignacio", ubicada en el departamento de Maldonado en Uruguay. La elección de este centro de estudios responde a varios factores. En primer lugar, su larga e ininterrumpida tradición docente, con 80 años de haber sido fundada, le confiere un alto potencial para indagar aspectos relevantes del estudio: variaciones en la percepción del paisaje y modificaciones acaecidas en éste a lo largo de prolongados períodos; relación con la idea de pertenencia al lugar; construcción, cambio y desaparición de hitos claves del entorno. En segundo lugar, cuenta con 50 alumnos, número elevado en comparación con otras escuelas rurales del país. Esta condición hace posible enmarcar el proceso de internalización del conocimiento en un contexto de aprendizaje entre pares por experiencias vivenciales, lo cual trasciende la óptica tradicional de exposición en el aula. Por último, la selección del área geográfica y en particular de la institución se fundamenta en la diversidad de paisajes presentes en la zona, la necesidad de generar conciencia de su valoración, y la detección de dinámicas de alteración acelerada que afectan e impactan el área. Laguna, costa y sierra se convierten en espacios territoriales de cambio constante cuya consideración requiere ser abordada desde tempranas etapas del aprendizaje.

Participaron maestras y niños de $4^{\circ}$ a $6^{\circ}$ grado en un aula común bajo el formato de Escuela Rural. Tras recorrer el área de la laguna José Ignacio se trabajaron talleres en el aula. Estos se enfocaron en las percepciones del entorno local, plasmadas mediante distintas técnicas de representación: relatos, dibujos individuales y car- 
tografías colectivas. El acercamiento al territorio se hizo a través de herramientas tecnológicas de visualización remota con el fin de establecer parámetros del paisaje, tales como vínculos entre escala y detalle, entre manzana, pueblo y región, percepción de ecosistemas locales y recorridos cotidianos. Se efectuaron vuelos de drones sobre la zona de indagación y se elaboraron cartografías del paisaje antes y después de usar estos dispositivos tecnológicos, para evaluar así aprendizajes a partir de la experiencia.

Las cámaras GoProHero 5 Session del equipamiento de registro fueron usadas de manera individual para diferentes tareas (panoramas, imagen fija, timelapse, video) y se asociaron en grupos de seis en la filmación de video 360 . Para el registro desde el aire se recurrió al dron DJIPhantom 4, con cámara de 4K. Este dispositivo facilitó tomas fijas, videos, panorámicas y barridos en varios planos, para componer imágenes de 360 grados, utilizadas en la plataforma interactiva.

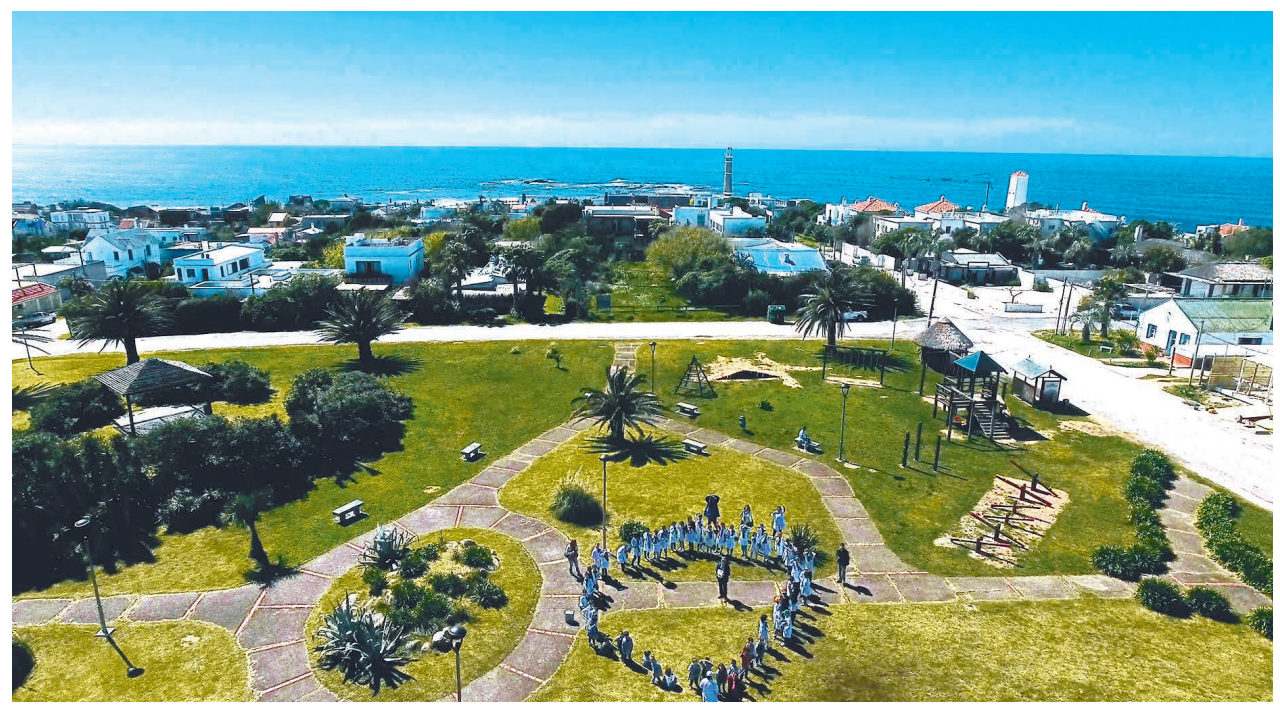

Figura 1. Procedimientos de registro desde el aire, octubre de 2017, José Ignacio, Uruguay.

Fotografía: Marcelo Payssé Alvarez.

Otra utilidad desarrollada fue la generación de panoramas de varias imágenes, asociadas luego para formar un casquete semiesférico, navegable de forma interactiva en la web. La imagen esférica que se despliega en pantalla resulta de la composición de 27 imágenes planas. Se creó una versión para dispositivos de pantalla táctil, la cual facilita los desplazamientos habituales en estos. 
Se abordaron las relaciones entre el nomenclátor de la localidad de José Ignacio y las aves de la región, con actividades de interacción entre maestros, niños y docentes universitarios. Igualmente, se verificó un itinerario geográfico que incluyó salidas didácticas y mapeos del recorrido. El punto de partida fue la escuela 88 y se visitaron otras instituciones educativas rurales de la región.

La plataforma digital no solo es accesible a los niños de la región de José Ignacio, sino de otras escuelas nacionales. Se apunta a replicar la experiencia en más centros educativos y generar, con la participación de alumnos, productos que permitan a otros niños conocer los diversos paisajes del país.

\section{ESTRATEGIA METODOLÓGICA}

La estrategia metodológica se relaciona con Learning Analytics al considerar la evaluación de aprendizajes a partir del uso de nuevos dispositivos tecnológicos (Brown, 2012). Se busca interpretar datos recogidos en las actividades con los educandos para definir e identificar elementos problemáticos o desafíos en la apropiación y el manejo de dichos dispositivos. De este modo se pretende apoyar ecosistemas de enseñanza más personalizados y acordes al uso de nuevas tecnologías. El proyecto incluye también la aplicación de análisis de contenido y de discurso para capturar datos significativos de las interacciones entre los niños, del lenguaje utilizado y las tecnologías incorporadas.

Dentro de esta estrategia, la investigación se organiza en tres etapas que se interrelacionan y retroalimentan. La primera es exploratoria y comprende el ajuste del marco conceptual y la revisión de antecedentes. En la segunda -más extensase desarrollan las principales actividades investigativas. La tercera y final consiste en la síntesis, evaluación y divulgación de resultados².

A lo largo de los doce meses de ejecución del proyecto (abril de 2017 a marzo de 2018) se concretaron cinco paquetes de trabajo o Work Packets (WP). El WP1 "Exploratorio", comprendió actividades de la fase inicial: revisión bibliográfica de antecedentes, planificación para involucrar a las maestras en el marco conceptual proyectual y preparación de actividades a cumplir con los niños del centro educativo en las etapas siguientes.

El WP2 “Laguna José Ignacio”, producido entre mayo y agosto de 2017, presentó actividades de observación del paisaje, sus transformaciones en el tiempo y afectaciones en la dinámica costera provocadas por factores climáticos y el proceso de poblamiento. Se generó un registro aéreo de las conexiones entre la laguna y el océano, como también de los elementos construidos en esa zona de

${ }^{3}$ Resultados parciales de la investigación se presentaron en noviembre de 2017 en el XXI Congreso Internacional de la Sociedad Iberoamericana de Gráfica Digital (Sigradi), en Concepción, Chile. La ponencia fue publicada (ver Goñi\&Payssé, 2017). 
litoral que impactan las dinámicas del paisaje. Además, en una visita a la laguna con la presencia de los niños y especialistas en botánica y ecología del equipo investigativo, se llevaron a cabo reconocimientos de flora y fauna. Esta salida fue seguida por jornadas en la escuela durante las cuales se realizaron cartografías colectivas sobre fotografías satelitales, escritos redactados por los estudiantes y dibujos. También se vieron videos con ediciones de tomas aéreas logradas desde los dispositivos de visualización remota y se trabajó a partir de este material.

El WP3 “Nomenclátor José Ignacio”, planteó tareas vinculadas con el casco urbano del pueblo y la vivencia allí de los niños. Incluyó varias actividades: una caminata con los alumnos por el pueblo oceánico y la observación in situ del nomenclátor; ejercicios didácticos en torno a las aves de la región; interacción con el dron, dispositivo que sobrevoló la escuela y otros lugares significativos del pueblo; y la síntesis y evaluación de aprendizajes.

El WP4 "Itinerario 88", abarcó lo concerniente al itinerario que partió de la escuela 88, “Faro de José Ignacio", y se dirigió a las escuelas 55, “Costas de José Ignacio”, y 39, "Sierra de Carapé". Junto a especialistas en botánica y ecología se reconoció el paisaje serrano, su flora y fauna y se interactuó de nuevo con el equipamiento de registro cuando este sobrevoló la Sierra de Carapé. Se dio así una integración de los niños de los tres centros educativos rurales.

El WP5 "Evaluación y Divulgación”, trató la sistematización de los trabajos realizados, la evaluación de aprendizajes, la elaboración de un documento escrito de síntesis y la generación de una plataforma digital interactiva, abierta en internet y asociada al Plan Ceibal. De forma complementaria, se diseñaron e imprimieron postales con reproducciones de dibujos hechos por los niños participantes. Este material sirvió para una más amplia divulgación.

Como cierre del proyecto, en marzo de 2018 se presentó públicamente la plataforma digital y se plantó un arbusto frutal autóctono (Arazá) en el patio de la escuela 88, como elemento simbólico y recuerdo vivo del proyecto hacia el futuro. Durante esta jornada, los investigadores recibieron comentarios de los niños acerca de las propias observaciones efectuadas por estos en el paisaje local. Entre otras, se mencionó la barra cerrada de la laguna José Ignacio, en oposición a la barra abierta reconocida en 2017, y la presencia de delfines en el océano, frente a la laguna. De tal modo, se corroboró el interés despertado hacia la apreciación del paisaje y de sus transformaciones entre la población escolar. 
En la evaluación de aprendizajes se tuvieron en cuenta tres métodos: la "analítica de contenidos", para las cartografías, los dibujos y relatos autoría de los niños; la "analítica de discurso", enfocada en los textos y las palabras empleadas en las actividades; y la "analítica para capturar datos", que considera la disposición de los alumnos respecto a su propio proceso educativo, la curiosidad e inclinación a preguntar y la captura de esta información para la evaluación (Coll, 2008).

\section{ANÁLISIS DE DATOS Y DISCUSIÓN}

La producción de los niños fue analizada cuantitativa y cualitativamente con la intención de identificar elementos que podían descubrirse en el proceso de aprendizaje, como también los conocimientos y las herramientas que se incorporaron. Para este análisis se formularon las siguientes preguntas guía:

- ¿Cuáles elementos se reconocieron en la observación in situ del paisaje?

- Cuando se trabajó con cartografías, ¿qué elementos se reconocieron en las imágenes aéreas y satelitales?

- ¿Qué evidencia la comparación entre las cartografías, los dibujos y relatos que se realizaron antes y con posterioridad al uso de las herramientas tecnológicas?

- ¿Se aprecian cambios en la percepción del paisaje a partir de la utilización de herramientas tecnológicas de visualización remota?

- ¿Se incrementa la comprensión de los vínculos entre escala y detalle o entre lugar y región?

En primer lugar, se evaluaron los relatos de los niños con la intención de captar datos a partir del lenguaje. El énfasis se puso en los términos más empleados, diferenciados en tres categorías: sustantivos, verbos y palabras valorativas. En la actividad 4.3, consistente en textos escritos tras la visita colectiva a la laguna, los sustantivos más recurrentes fueron: laguna, cangrejos, puente, agua, flamencos, arena, mar, aves, gaviotas, paisaje. Los verbos, en las formas conjugadas como se utilizaron, fueron: vi, pasamos, fuimos, conocí, hablamos, tocamos, escalamos, oímos. En las 
palabras valorativas aparecieron: me gustó, me interesó, me llamó la atención, me divertí, día espectacular. En la actividad 6.3 (relatos luego de ver videos y fotografías satelitales de la laguna) los sustantivos fueron: dron, flamencos, agua, laguna, vegetación, puente, video, cactus, sombra, olas. Verbos: parecía, filmaba, saludaron, acercó, aprendí. Palabras valorativas: me gustó, me interesó, espectacular, fue genial, impresionante. En la actividad 9.1 (relatos escritos después de conocer directamente el dron y verlo funcionar), los sustantivos fueron: dron, cámara, grabación, hélices, fotografías, batería, luces. Verbos: volaba, grabar, sacar fotos, moverse, giraban, conectaba, pienso, inclinarse, localizar, prender. Palabras valorativas: me gustó mucho, me divertí, fue genial. En la actividad 11.3 (realizada después de ver el video del dron sobre la sierra) se escribió un relato a partir de la consigna: “¿Qué diferencias encuentras en lo que ves respecto a lo que veías en anteriores vuelos del dron?". Los sustantivos más reiterados fueron: escuela, agua, niños, molinos, diferencia, sierras, vegetación, campo, paisajes, calles, juegos, colores, ríos, maestros, monte ribereño. Los verbos: aprendimos, vi, fuimos, trabajamos, tienen. En este caso no se usaron palabras valorativas.

En primer término, mediante el comparativo de sustantivos entre las cuatro actividades, se constató la incorporación progresiva de palabras asociadas con la tecnología, in crescendo hacia el ejercicio 9.1, en el que se produce su mayor cantidad y diversidad. Sin embargo, en la actividad 11.3 esta tendencia cambia y casi no se registran términos relacionados con tecnología. Se estima que tal variación se debe a la consigna enunciada, pues esta pone el énfasis en las diferencias entre el más reciente vuelo del dron y los previos, razón por lo cual la atención se centra en tal contraste y se desvía de los elementos tecnológicos.

En segundo término, en relación con los verbos en los relatos, se identificó una tendencia similar a la anotada en los sustantivos en cuanto al uso progresivo de palabras vinculadas con tecnología. El clímax se da en la actividad 9.1 mientras que en la 11.3 esta tendencia cambia y no hay verbos asociados con tal campo.

$\mathrm{Al}$ analizar las palabras valorativas en los relatos, para la primera actividad se encontró un uso moderado y austero de estas, la 4.3 fue en esencia descriptiva, en la 6.3 crecen en intensidad y en cantidad, para llegar al máximo en la 9.1. Las valo- 
raciones hechas por los niños de forma creciente en los sucesivos ejercicios reflejan apropiación de las temáticas abordadas y también confianza en la inmersión en las actividades planteadas, lo cual se expresa en términos asociados a gusto, placer, diversión, complicidad e interés en aumento. En la 11.3 no se revelaron palabras valorativas, si bien en este punto la consigna se dirigía a un trabajo de comparación entre diversos vuelos del dron, de modo que el resultado fue más objetivo, menos valorativo y en varios casos dibujado a modo de tabla comparativa de sustantivos, como alternativa al relato escrito.

Salir de la escuela es de por sí una motivación que capta la atención de los escolares. Si a esto se suma el hecho de experimentar un recorrido por un camino no habitual, ir desde la laguna hasta el mar, pasar por debajo del puente, observar de cerca aves y otros animales, aproximarse a habitantes ocupados en tareas vinculadas a los recursos naturales y conversar con estas personas, se tiene entonces una serie de componentes que juntos despiertan y estimulan la curiosidad de los niños y hacen de ellos participantes activos en la construcción del conocimiento sobre el lugar. A partir de la lectura de sus breves textos es posible construir una descripción valorativa del paisaje en la cual se reúnen elementos ecológicos y antrópicos. Posteriormente, en los relatos posvideo y posdron aparecen otro tipo de reflexiones, como aquellas sobre las posibilidades del instrumento, su utilidad, la percepción de detalles no reconocidos previamente, la incorporación del concepto de escala y de un lenguaje diferente.

Al analizar los dibujos creados por los alumnos aparece el código gráfico, distinto al de lectoescritura. Dibujar el entorno vital pone de manifiesto los puntos de referencia espaciales de los educandos, sus diversos grados de conocimiento del territorio donde habitan y sus valoraciones hacia el paisaje que perciben. 
En los dibujos realizados individualmente por los menores, se evaluaron elementos clave que aparecían dibujados y su frecuencia de registro. En la actividad 4.1, tras la visita colectiva a la laguna, los más registrados fueron: agua, arena, sol, puente, cangrejos, nubes, pájaros, rocas, casas y botes (figura 2). Los elementos que conforman la matriz dominante del paisaje visual de la laguna desde un horizonte peatonal: agua y arena, aparecen en primer lugar y dan paso a otros de escala menor (cangrejos, pájaros, casas) que aparecen con menor frecuencia de registro. Con estos datos se verifica el valor del dibujo como herramienta para evaluar la comprensión en los educandos de los vínculos entre escala y detalle en la observación paisajística.

En la actividad 6.1, llevada a cabo luego de ver los videos de la laguna, se consignaron con más frecuencia: laguna, agua, vegetación, puente, océano, isla, arena (figura3). Aparecen elementos que conforman la matriz dominante del paisaje desde las visuales aéreas apreciadas en las fotos satelitales y en los videos filmados desde el dron. Laguna, vegetación, puente y océano, son destacados por los alumnos. Luego se encuentra un segundo grupo, con menos repeticiones, de elementos de menor escala pero importantes en el contexto (cercos, dron) y otros que conforman el fondo escénico (horizonte, montañas). Nuevamente se constata la utilidad del dibujo como herramienta para plasmar la comprensión de los vínculos entre escala y detalle en la observación paisajística. 


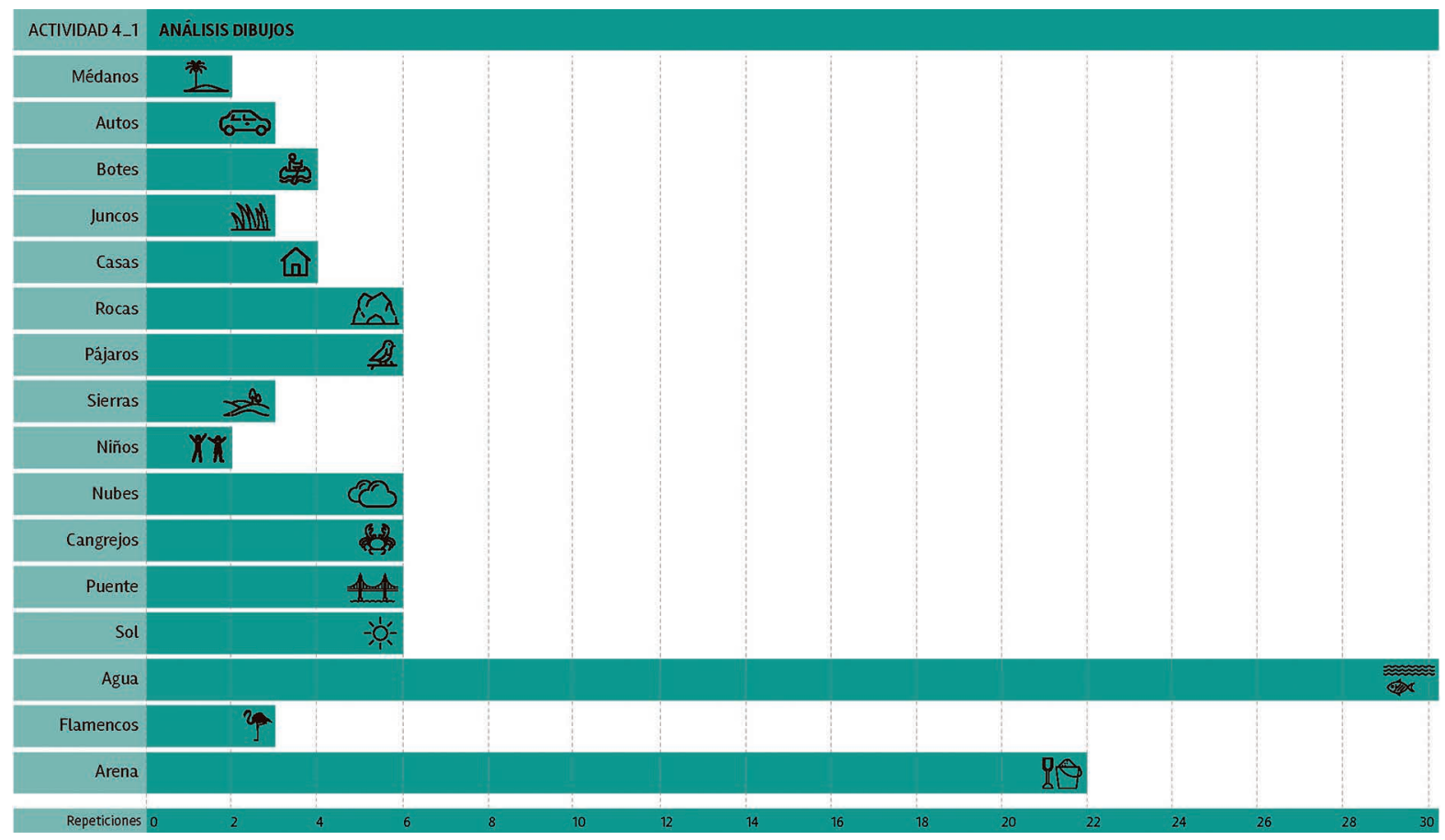

Figura 2.Análisis de la actividad 4.1 / WP2 Laguna José Ignacio. Fuente: Elaboración propia.

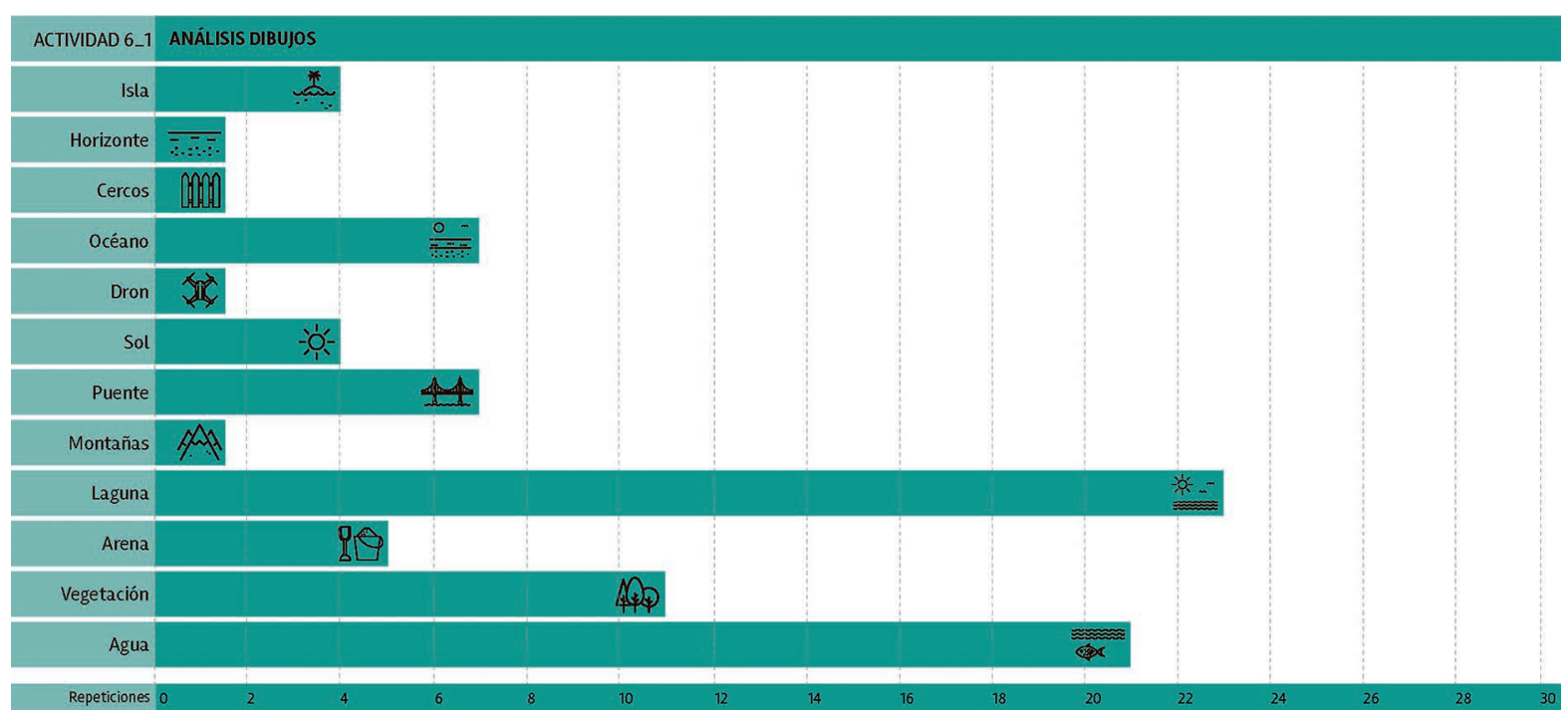

Figura 3.Análisis de la actividad 6.1 / WP2 Laguna José Ignacio. Fuente: Elaboración propia. 
El análisis comparativo de las actividades 4.1 y 6.1, realizadas antes y después de la interacción con los videos grabados desde el dron sobre la laguna, evidencia un cambio en los elementos dibujados más frecuentemente. Mientras que en 4.1 sobresalen agua y arena como dominantes del paisaje (apreciados desde un horizonte peatonal), en 6.1 destacan otros que implican la adopción del punto de vista aéreo gracias a los videos (silueta de la laguna, vegetación, océano, puente). El cambio del horizonte normal al aéreo es registrado así en los dibujos como una ampliación de la capacidad de ver nuevos componentes del lugar.

En la actividad 4.2, cuya consigna era dibujar un mapa que mostrara la silueta de la laguna, se registraron con mayor frecuencia: laguna, barra laguna, vegetación borde laguna, arena, océano, puente y borde costero. En la 6.2, posterior al reconocimiento de fotografías aéreas históricas del cuerpo lacustre, se tuvo: borde costero, playa, agua, año 2016, laguna José Ignacio, año 1943, arena, barra laguna, vegetación, océano, laguna Escondida y laguna de los Flamencos. En esta instancia empieza a incorporarse nuevo vocabulario y a ser empleado con acierto. Las imágenes permiten distinguir hitos en el paisaje, como son la propia laguna José Ignacio, la Escondida y la de los Flamencos. A su vez, en los dibujos se registran fechas claves de los registros fotográficos, entre ellas la del vuelo histórico Trimetrogon del Servicio Geográfico Militar (año 1943) y referencias a fotos satelitales más recientes (2016) de Google Earth. Se identifican transformaciones paisajísticas de la región José Ignacio, como la ocurrida con el cordón dunar, donde la arena era la matriz dominante del paisaje en 1943, pero la antropización producida a través de la forestación y la urbanización progresiva del territorio han modificado en su totalidad aquel paisaje histórico (figura 4). 

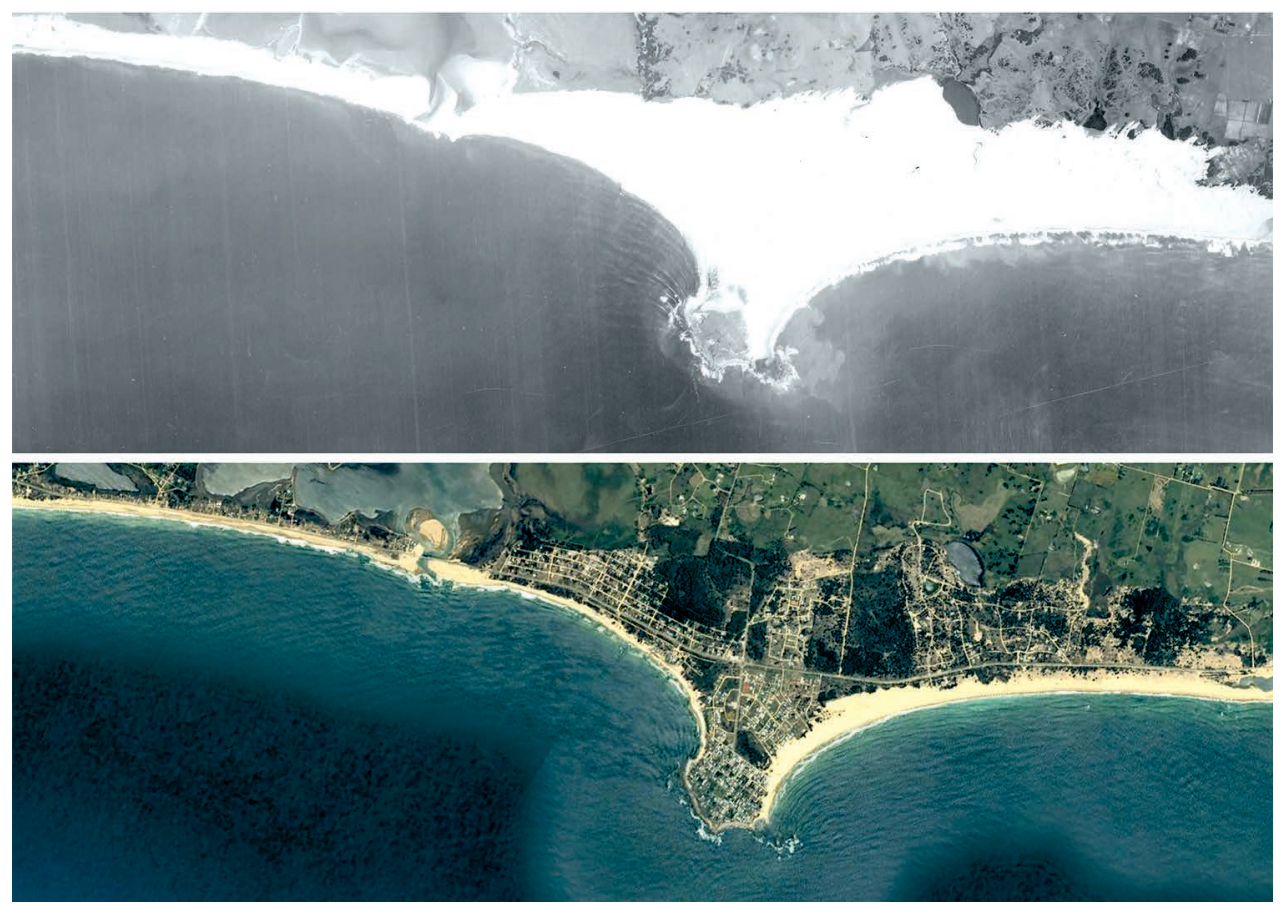

Figura 4. Transformación del paisaje en el tiempo Fuente: Elaboración propia con base en fotografía aérea SGM, vuelo histórico Trimetrogon, escala 1:40.000, año 1943 (arriba) y fotografía satelital de Google Earth, 2016 (abajo).

En las cartografías elaboradas colectivamente por los alumnos, los componentes paisajísticos más frecuentes son los observados con frecuencia por ellos mismos en sus recorridos cotidianos. En la actividad 6.4 se elaboró una cartografía grupal a partir de una fotografía satelital de 2016 de la región de José Ignacio, obtenida de Google Earth. Al indicar las rutas diarias y los sitios a visitar, la franja costera apare- 
ció como la más transitada, aunque también se destacaron recorridos sobre el agua, al interior de la laguna, por parte de niños integrantes de familias de pescadores. Otros componentes del paisaje permanecieron ocultos en estas cartografías, dadas las dificultades para su acceso físico y visual (figura 5).

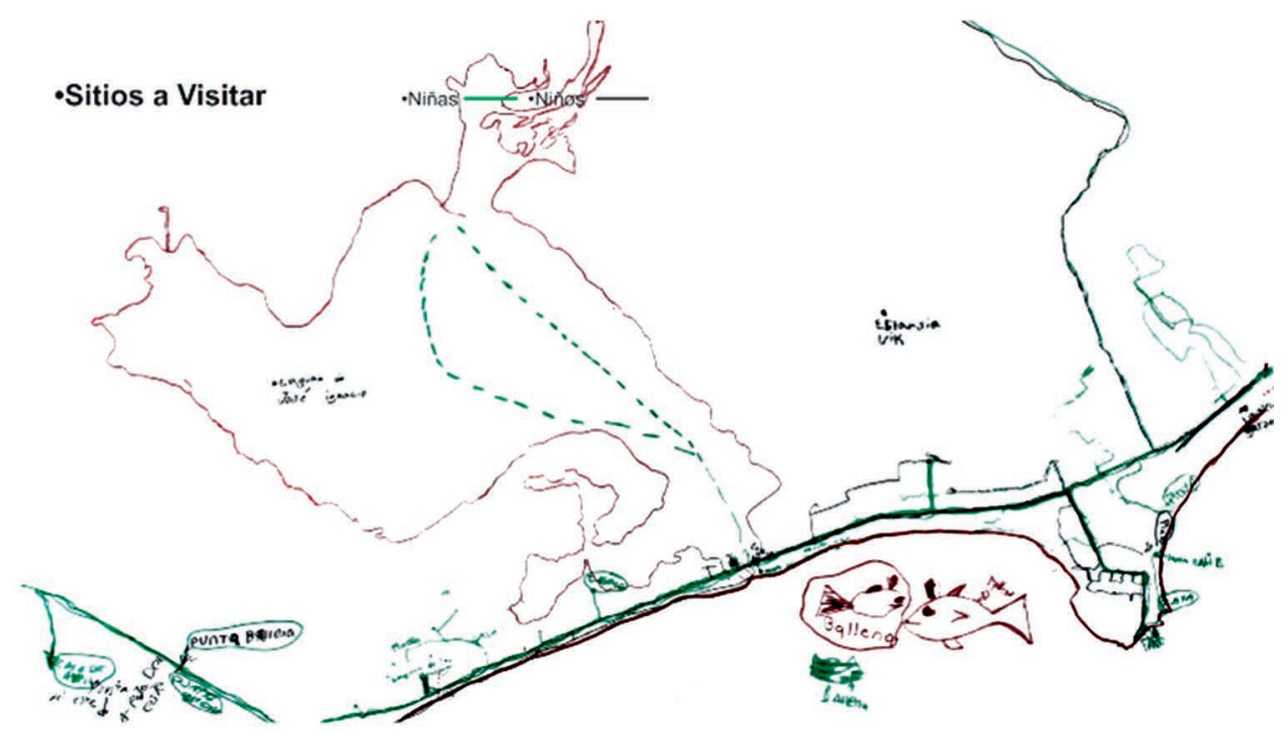

Figura 5. Cartografía colectiva, actividad 6.4 / WP2laguna José Ignacio. Fuente: Elaboración propia.

El estas cartografías, el dibujo sirve como herramienta clave para la comprensión de los vínculos entre lugar y región al observar el paisaje. Se manifiestan relaciones de cercanía y lejanía entre laguna y pueblo oceánico, entre ruta y borde costero, al igual que referencias a sitios más lejanos como Punta Ballena.

La actividad 8.1 tuvo lugar luego de la caminata colectiva por el pueblo José Ignacio, durante la cual se observó su nomenclátor. Los elementos registrados con más frecuencia fueron: cisne, agua, picaflores, garzas, teros, horneros, sol, nido, flor, totoras, peces, gaviotas, biguá, golondrinas, tordos, juncos (figura 6). 


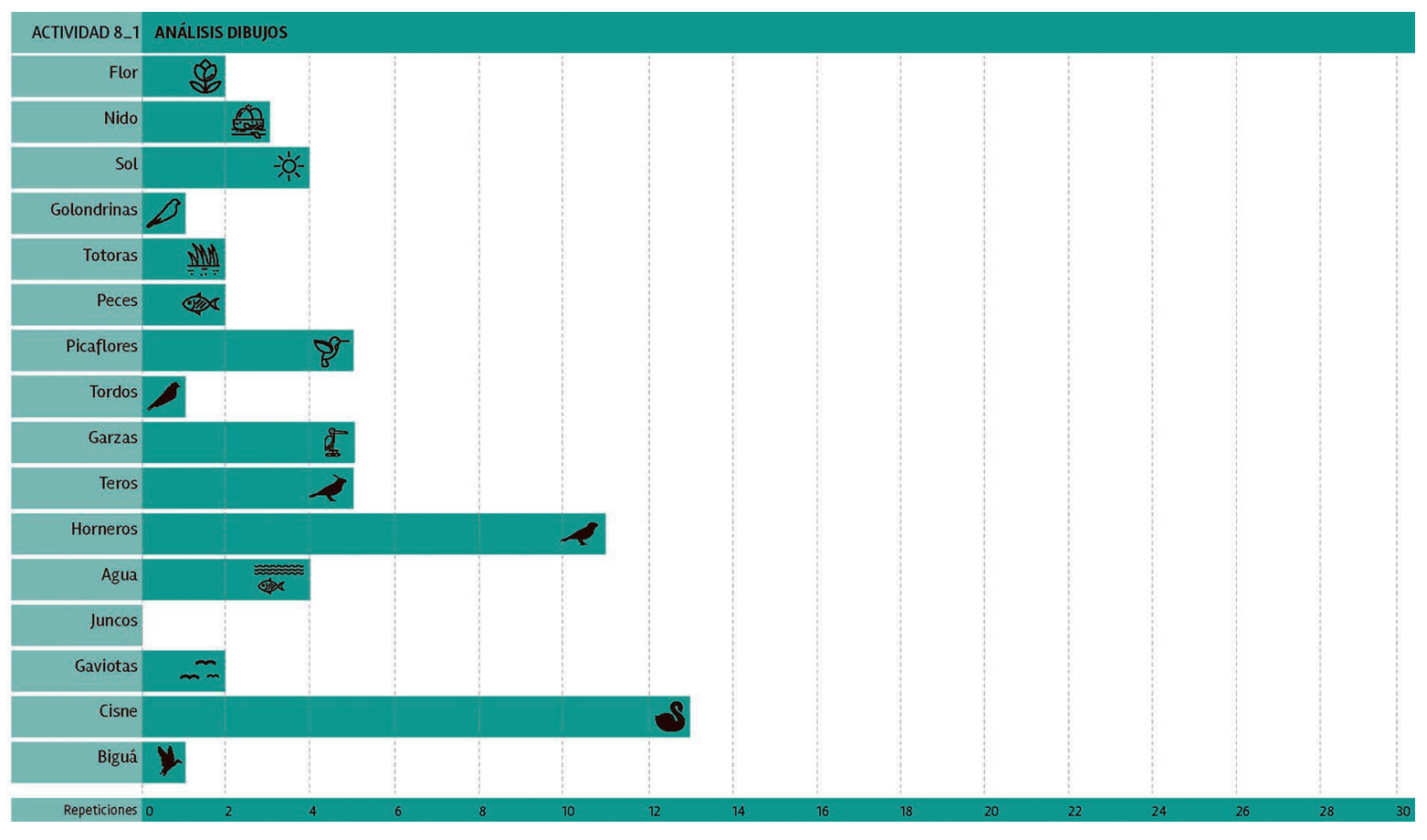

Figura 6. Análisis de la actividad 8.1 / WP3 Nomenclátor José Ignacio. Fuente: Elaboración propia.

Es preciso resaltar la mayor recurrencia en los dibujos de aves con las cuales los niños interactúan a diario. Así ocurrió con los horneros, de los que se encontró un nido sobre la puerta de la escuela, o los cisnes, pues varios estudiantes han tenido la experiencia de criarlos en sus propias casas dada la cercanía de estas con la laguna. Sobresalen también elementos paisajísticos como flores, nidos, totoras, sol y agua, todos vinculados con estos animales, a los que se asocia con su hábitat y con cuanto frecuentan para su alimentación y descanso. Durante esta actividad se efectuó un recorrido virtual sobre mapas por las calles de José Ignacio, se reconocieron aves y se les dibujó. Se leyó además la Guía para la identificación de las aves de Argentina y Uruguay (Narosky\&Yzurieta,2003). La información sobre características de las especies, su hábitat y comportamiento fue asimilada por los educandos y reproducida en sus dibujos.

En la misma jornada centrada en el nomenclátor de José Ignacio se hizo la lectura de Esmeraldina, cuento perteneciente a Las ciudades invisibles de Italo Calvino (1994) que habla de una ciudad imaginaria habitada por golondrinas. Las golondrinas es, precisamente, el nombre de la calle de la escuela 88. Posteriormente, el 
grupo de investigación elaboró una serie de fichas con datos de las aves contenidas en el nomenclátor del pueblo. Se recurrió a un formato comunicacional dirigido a los niños, con fotografías tomadas por miembros del equipo e incorporadas a la plataforma digital (figura 7).

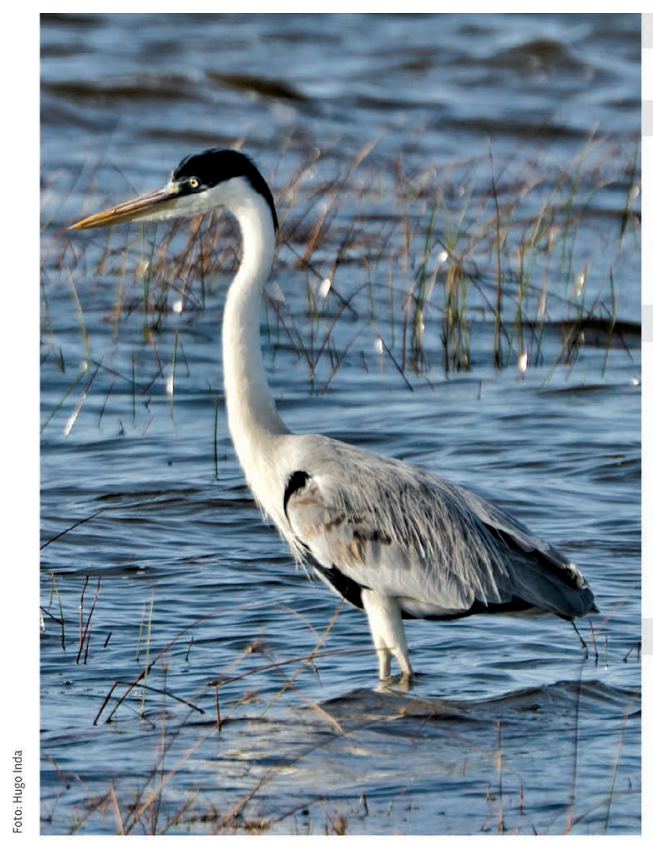

\section{GARZA MORA \\ Familia: Ardeidae \\ ¿CÓMO ES?}

Es la garza de mayor tamaño, mide unos $75 \mathrm{~cm}$. Tiene en la parte superior de la cabeza plumas alargadas y negras. Su dorso es gris y el resto del cuerpo de color blanco.

\section{¿CÓMO SE COMPORTA?}

Se la observa sola o en pareja. Se suele posar sobre los árboles o en la orilla del río para acechar a sus presas. Su vuelo es pausado y majestuoso. Como alarma emite una voz áspera y grave.

Se alimenta principalmente de peces y de culebras, ranas, insectos, anfibios y crustáceos.

El nido tiene la forma de una plataforma grande, realizada con juncos y agregado de palitos o ramitas.

\section{¿DÓNDE LO ENCONTRAMOS?}

Habita en ambientes acuáticos: esteros, lagunas, charcos, islas, orillas de arroyos y de rios

Lo encontramos desde Panamá hacia el cono sur.

Figura 7. Ejemplo de ficha de aves, WP3 Nomenclátor José Ignacio.

Fuente: Elaboración propia.

En la actividad 11.1, que tuvo lugar después de la visita a la escuela 39 en Sierra de Carapé, los elementos más recurrentes fueron: vegetación, escuela, pradera, árboles, sol, arroyo, niños, flores, sierras, bus de Turismar, ruta, bandera, maestra, alambrado, dron, aves y agua potable (figura 8). El dominio de lo asociado con el reino vegetales notorio: pradera, árboles, vegetación, flores, se reiteran en los dibujos junto al verde, color predominante en la gran mayoría.

La actividad 11.2 se cumplió con posterioridad a la salida didáctica a la Sierra de Carapé y del ejercicio de reconocimiento de flora indígena. Los elementos registrados con mayor frecuencia fueron: árboles, ramas, hojas, suelo, flores, sol, raíces, cielo, anacahuita, ceibo, ramilla, sauce, espina de la cruz, rosa, curupí, acacia mansa, helecho y verbena roja (figura 9). 

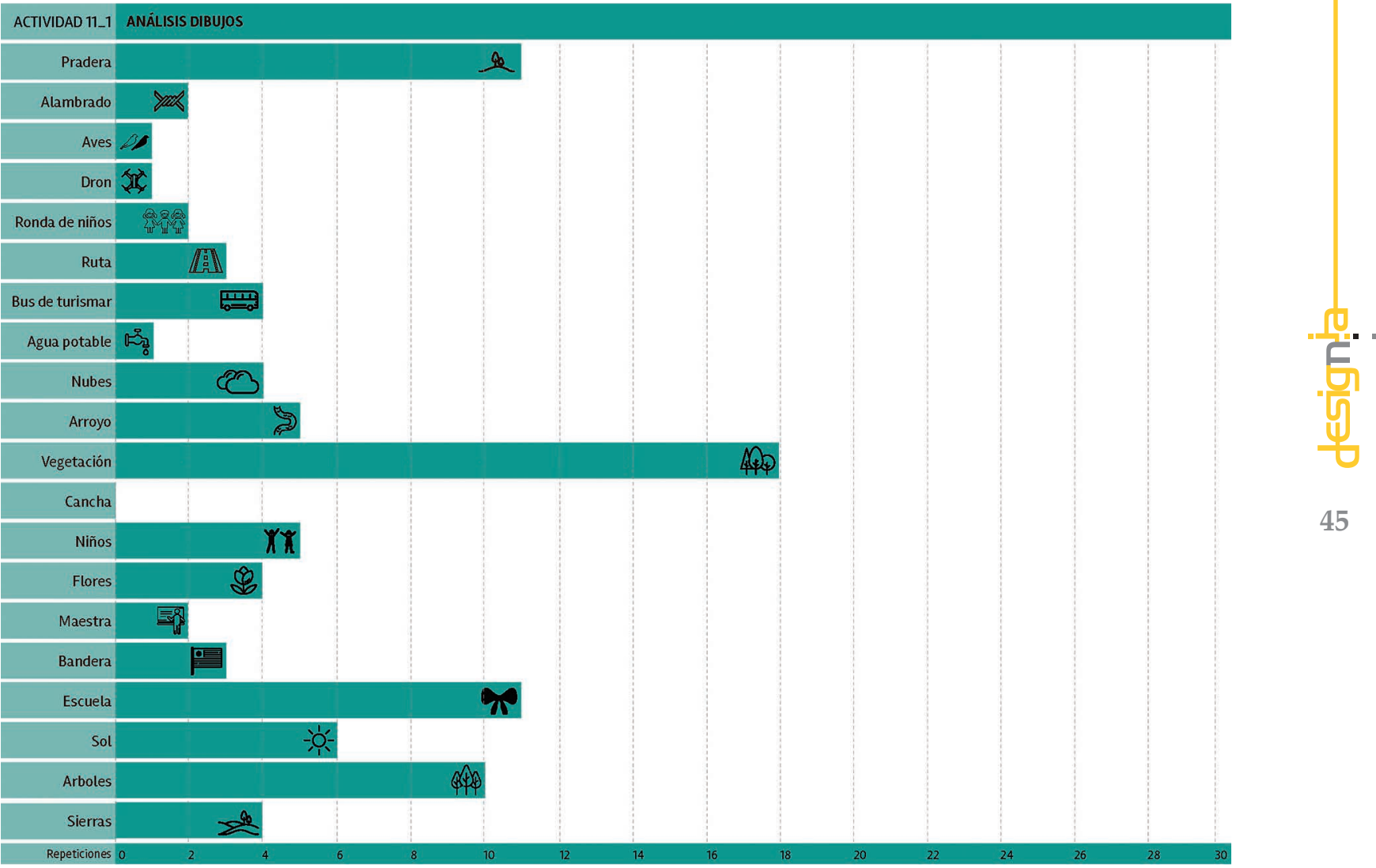

45

Figura 8. Análisis de la actividad 11.1 / WP4 Itinerario 88.

Fuente: Elaboración propia. 


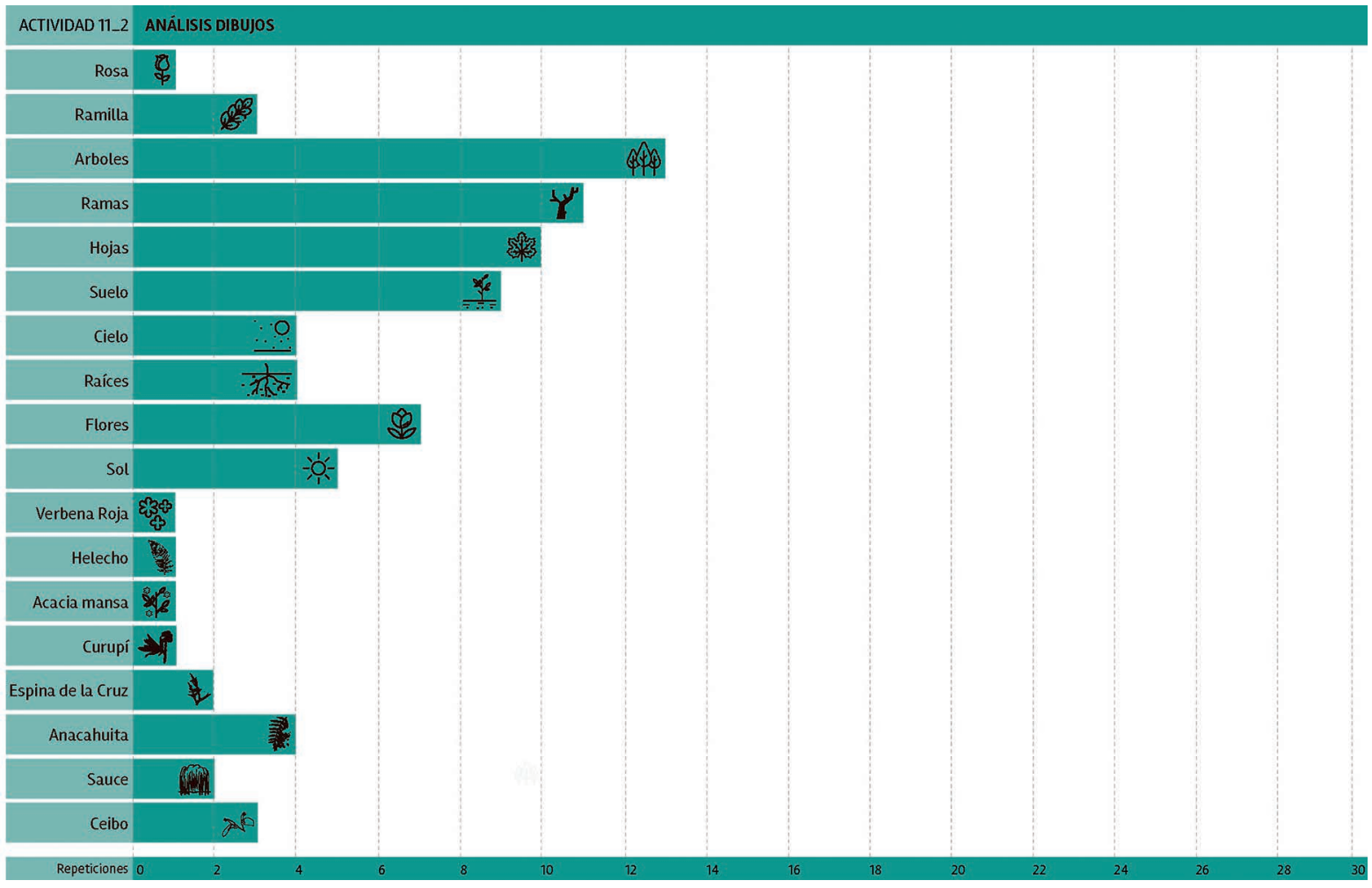

Se reflexionó a partir de la vegetación observada y de sus componentes sobresalientes en el paisaje (flores, frutos, cortezas, ramillas). Se mostraron en el aula las acuarelas de distintas especies, autoría de Pedro Cracco, reproducidas en el libro Flora indígena del Uruguay (Muñoz, Cracco \& Ross,1993) y se ensayó el dibujo de ejemplares vegetales con los alumnos. Adicionalmente, con la asesoría del Ingeniero Agrónomo Pablo Ross, el equipo de investigación consolidó una serie de fichas que aporta información de cada especie vista en la excursión, de su comportamiento y hábitat. Este material se adaptó en formato comunicacional destinado a los niños y se incorporó a la plataforma digital (figura 10). 


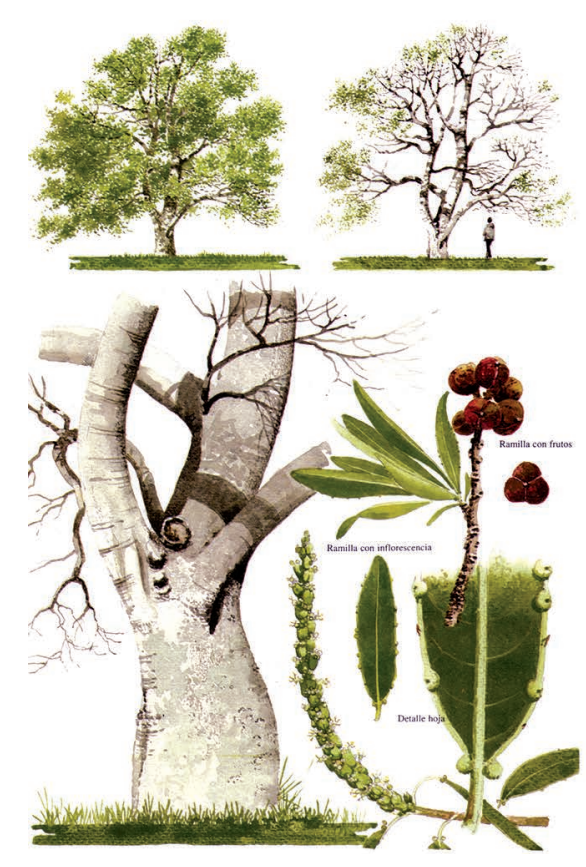

CURUPI O ARBOL DE LA LECHE Sapium Montevidense

Familia: Euphorbiaceae

¿CÓMO ES?

Es un árbol robusto de entre 7 y $8 \mathrm{~m}$ de altura con tronco algo tortuoso de color castaño, corteza fina, persistente y copa redondeada. Su follaje es semipersistente a caduco de color verde claro. Sus hojas son simples, alternas, con forma de elipse y de $12 \mathrm{~cm}$ de largo con borde finamente aserrado. Las hojas tienen dos pequeñas glándulas productoras de látex. Su fruto es tricoco de $1 \mathrm{~cm}$ de diámetro, rojizo cuando está maduro.

\section{¿CÓMO SE COMPORTA?}

Florece en primavera con flores pequeñas sin pétalos dispuestas en espigas. Tiene flores femeninas en la mitad inferior y masculinas en la parte superior.

\section{¿DÓNDE LO ENCONTRAMOS?}

Es indigena de las zonas tropicales y subtropicales. En Uruguay la encontramos en lugares bajos y húmedos.

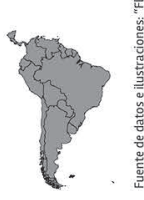

Figura 10. Fichas de vegetales, WP4 Itinerario 88.

Fuente: Elaboración del equipo de investigación con el asesoramiento del Ing. Agr. Pablo Ross.

\section{RESULTADOS FINALES}

El primer resultado es la verificación del potencial del paisaje como mediador en el desarrollo de nuevas pedagogías y en la incorporación de nuevas tecnologías.

En segundo lugar y en relación con el proceso desarrollado, es pertinente mencionar varios puntos: se trabajó en la promoción del aprendizaje activo al posicionar a los niños como principales protagonistas; se colaboró en el desarrollo de competencias para la acción; se aportó a la formación de capacidades para imaginar; se motivó una disposición hacia la búsqueda y construcción de conocimiento; se promovió un ambiente educativo en que se enlazó lo conocido con lo nuevo para ayudar a establecer conexiones.

En tercer lugar, se constató que el uso de herramientas tecnológicas de visualización y sensoramiento remoto facilita el reconocimiento del paisaje. Plataformas interactivas y dispositivos de sensoramiento se pusieron al servicio de las inquietudes de los niños como recursos para aprender acerca de las principales características del 
entorno ambiental y cultural local. Asimismo, estos instrumentos fueron abordados como una oportunidad para difundir los alcances de las Tecnologías de Información y Comunicación en el ámbito escolar, para lo cual se recurrió a explicaciones, experimentación y reflexiones sobre los nuevos medios aplicados al registro paisajístico en un contexto educativo.

Finalmente, se presentó la plataforma digital interactiva, disponible como página $w e b$ en el sitio http://www.plapp.edu.uy (figura 11). Esta tiene siete puntos de observación con capacidad de visión 360 grados y otros puntos sensibles que despliegan información adicional (fichas de vegetales y de aves, timelapse de cambios temporales en la morfología costera, entre otras opciones). Las visuales pueden ocupar toda la pantalla y a través de menús auxiliares, disponen de ayudas para la navegación y posibilidades de orbitar, cambiar de ubicación, agrandar y capturar la imagen. Con los niños de la escuela 88 se realizaron pruebas de este producto específico. Se incluyó también una divulgación regional al invitar a otras escuelas rurales a participar de las actividades finales.

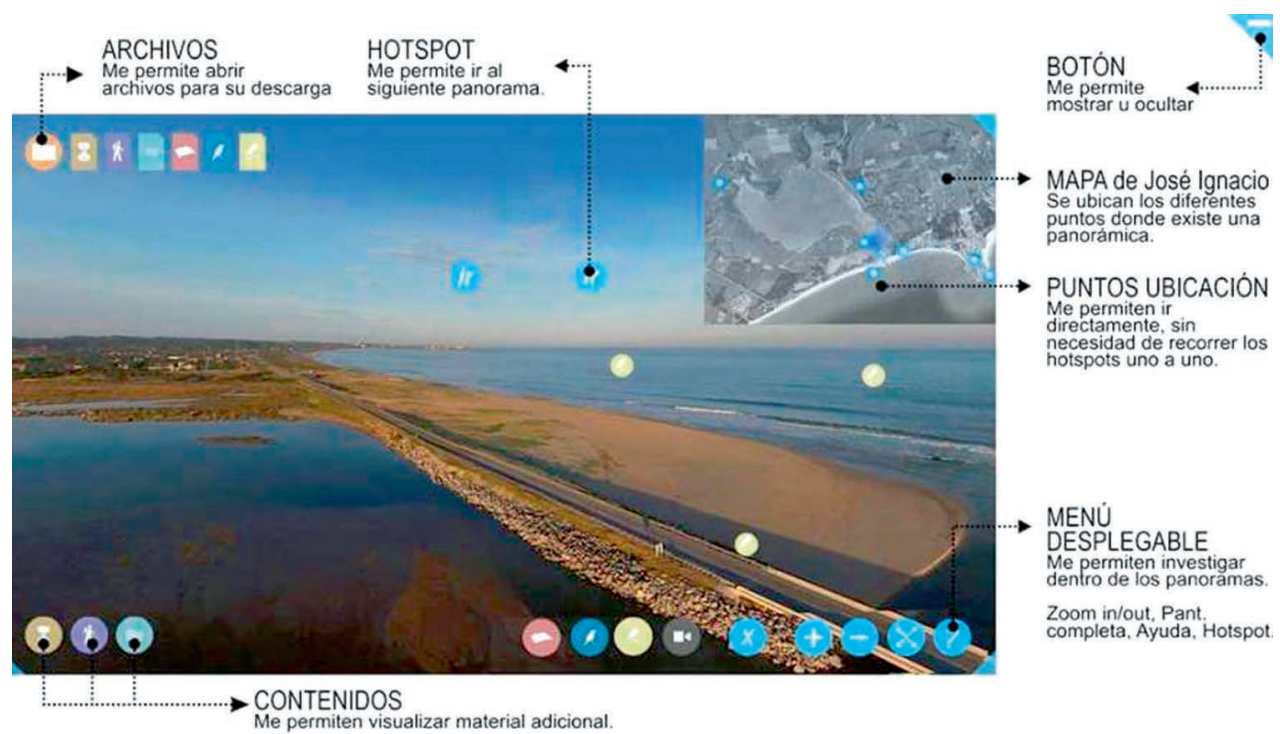

Figura 11. Plataforma Paisajes Pedagógicos, disponible en http://www.plapp.edu.uy Fuente: Elaboración propia. 
El equipo de investigación evalúa que estas herramientas tecnológicas remotas de sensoramiento y visualización posibilitan aprendizajes significativos. Así se ha verificado en esta experiencia mediante el análisis y la comparación de las cartografías del paisaje y de los relatos escritos por los niños, tanto previa como posteriormente a la utilización de dichos recursos. La metodología aplicada busca apoyar espacios de enseñanza y aprendizaje escolar más apropiados para el uso de nuevas tecnologías. En este sentido y a modo de síntesis, señalamos como aportes del proceso verificado los siguientes:

- El ensayo con el dispositivo tecnológico como un estímulo al desarrollo cognitivo del niño y con una incidencia en su aprendizaje.

- La generación de conocimiento sobre el paisaje en el área de actuación del proyecto y el estudio específico de la relación entre la manifestación visual del lugar analizado y su funcionamiento.

- La profundización en el conocimiento del espacio territorial regional que sirve de hábitat a la comunidad escolar.

- La plataforma digital en que los contenidos se presentan en un formato comunicacional adecuado a la población escolar participante de la investigación.

- La incorporación de nuevas tecnologías como herramientas facilitadoras de la apropiación e internalización de conocimiento por parte de los alumnos. 


\section{RECOMENDACIONES Y REFLEXIONES FINALES}

Esta experiencia verifica el potencial del paisaje como mediador de aprendizajes. El reconocimiento efectuado promueve en los educandos la identificación y apropiación de su entorno desde una práctica valorativa de lo ambiental y lo cultural. De tal forma, este emprendimiento constituye una base temprana de comprensión y reflexión acerca del territorio local y hacia su gestión sustentable.

Se recomienda replicar la experiencia en otras escuelas del país. Por su diseño metodológico (tabla 1), este proceso-producto es replicable y, en consecuencia, se pretende extenderlo a futuro con nuevos proyectos. Cada centro educativo debe trabajar en un contexto definido por su ubicación territorial, su trayectoria y las expectativas de su comunidad, de manera que las propuestas tendrán variaciones, de acuerdo con circunstancias específicas. La plataforma generada a partir del trabajo en la escuela 88 se visualiza como el inicio de un recurso semejante aunque más abarcador desde el cual los centros educativos puedan compartir el conocimiento sobre sus paisajes locales. Por lo tanto, el itinerario no ha de ser único pues si bien se encontrará orientación en objetivos similares, los trayectos serán trazados por cada caso particular.

Esta experiencia contribuye a la formación de los niños participantes y, a través de ellos, de sus familias. Se favorece así una mejor comprensión del hábitat y se perfila una estrategia de sostenibilidad apoyada en la comunidad escolar. 


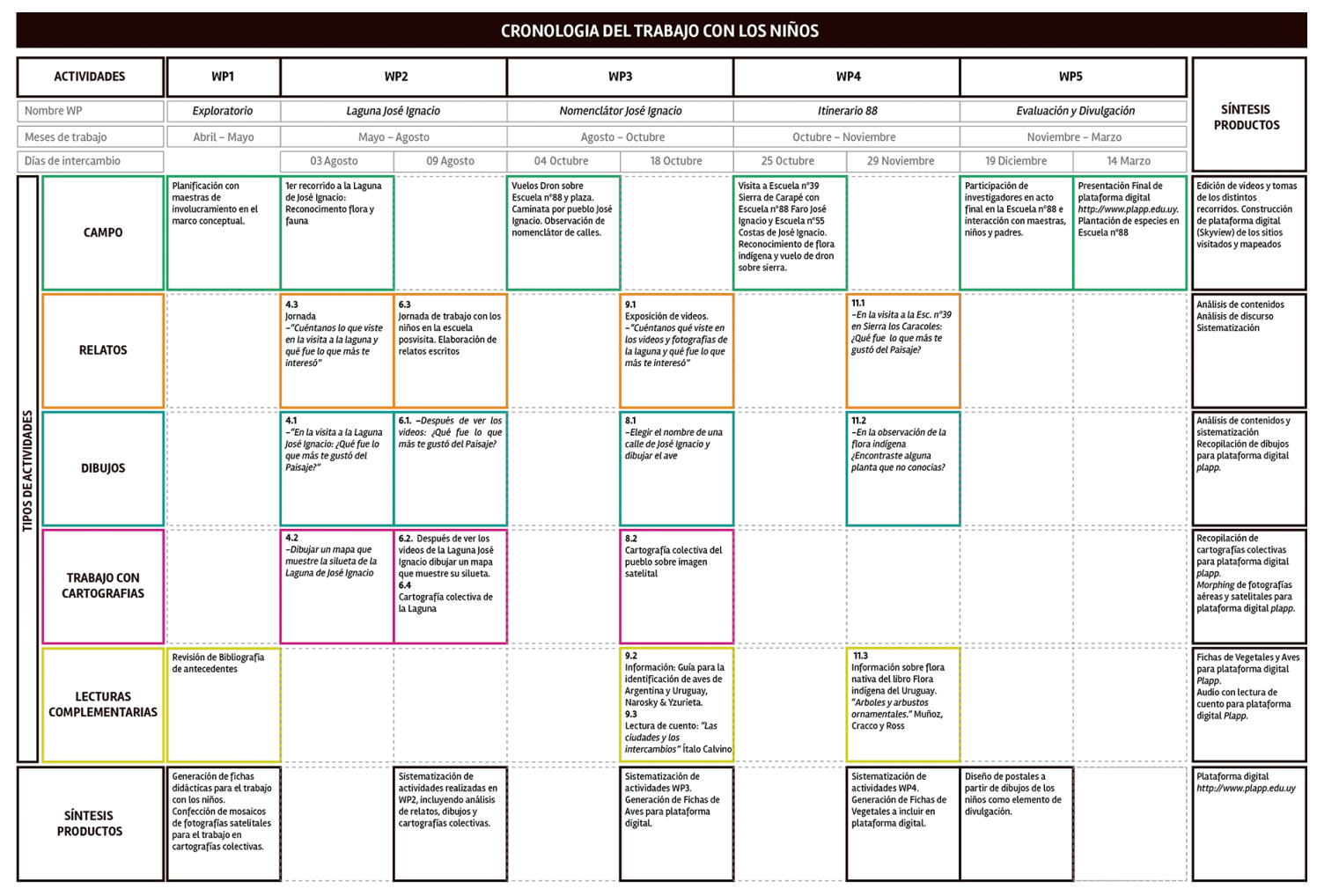

Tabla 1.Síntesis del cronograma, las actividades y los resultados. Fuente: Elaboración propia.

\section{AGRADECIMIENTOS}

Agradecemos a la entidades y organizaciones patrocinadoras y facilitadores de la investigación: ANII, Ceibal, FSED, CSIC.

A la directora de la escuela rural 88 "Faro José Ignacio", Maestra Silvia Rivas, como también a Nilvia Ferrizzo, maestra de $4^{\circ}$ a $6^{\circ}$ grado de la institución educativa, y a todos los niños participantes.

A los consultores y colaboradores del equipo del proyecto "El paisaje como mediador de nuevas pedagogías y tecnologías": Pablo Ross, Victoria Sánchez, William Pérez, Victoria López, Fernando García, Luis Flores y Lucía Meirelles. 


\section{REFERENCIAS BIBLIOGRÁFICAS}

Besse, J. (2010).El espacio del paisaje. Consideraciones teóricas. En T. Luna \& I.Valverde,(Dir.). Teoría y paisaje: reflexiones desde miradas interdisciplinarias (pp.7-24). Olot, España: Observatorio del Paisaje de Cataluña; Barcelona, España: Universidad Pompeu Fabra.

Brown, M. (2012).Learning Analytics: Moving from Concept to Practice. En Educause Review, Learning Initiative Briefing. On line at: library.educause.edu/resources/2012/7/learning-analytics-moving-from-concept-to-practice

Busquets, J. (2011).La importancia de la educación en paisaje. En J. Nogué (Ed.). Paisatge i educación (pp.378380). Olot, España: Observatorio del Paisaje de Cataluña.

Calvino, I. (1999). Seis propuestas para el próximo milenio. Madrid: Siruela.

Calvino, I. (1994). Las ciudades invisibles. Madrid: Siruela.

Carnahan, C.,Crowley, K. \&Zieger, L. (2016). Drones in education. Let's your student's imagination soar. New Jersey: International Society for Technology in Education.

Castiglioni, B. (2011).La educación en paisaje desde la óptica del Convenio Europeo del Paisaje y nuevas perspectivas. En J. Nogué (Ed.). Paisatge i educación (pp.386-388). Olot, España: Observatorio del Paisaje de Cataluña.

Coll, C. (2008).El análisis de los procesos de enseñanza y aprendizaje mediados por las TIC: una perspectiva constructivista. En E. Barberà, T. Mauri \& J. Onrubia (Ed.). La calidad educativa de la enseñanza basada en las TIC. Pautas e instrumentos de análisis (pp. 47-60). Barcelona: Graó.

Corner, J. (Ed.).(1999). Recovering Landscape. Essays in Contemporary Landscape Architecture. New York: Princeton Architectural Press.

Fandiño, L. (2008). La pedagogía de la creatividad. El uso del guión multimedia. Córdoba, Argentina: Fojas Cero.

Folch, R. \& Bru, J. (2017). Ambiente, territorio y paisaje. Valores y valoraciones. Barcelona: Barcino.

Fullan, M. \&Langworthy, M. (2014). A rich seam. How new pedagogies find deep learning. Londres: Pearson. 
Goñi, A. L. (2012).La condición del paisaje como construcción perceptiva. En M. Sánchez \& M. Fernández (Coord.). Paisaje y entorno: reflexiones multidisciplinares (pp.68-76). Murcia, España: Biovisual.

Goñi, A. L. \& Payssé, M. (2017).Inclusión digital. Educación con nuevos horizontes. Blucher Design Proceedings, 3(12), 120-124. DOI: 10.5151/sigradi2017-019

Hernández, F. (2011). Pensar la relación pedagógica en la universidad desde el encuentro entre sujetos, deseos y saberes. Barcelona: Universitat de Barcelona.

Kakaes, K. (Ed.).(2015). Drones and aerial observation: new technologies for property rights, human rights and global development. New America, online at www.newamerica.org

Lynch, K. (1960). La imagen de la ciudad. Buenos Aires: Infinito.

Maderuelo, J. (2005). El paisaje, génesis de un concepto. Madrid: Abada.

Muñoz, J., Cracco, P. \& Ross, P. (1993). Flora indígena del Uruguay: árboles y arbustos ornamentales. Montevideo: Hemisferio Sur.

Narosky, T. \& Yzurieta, D. (2003). Guía para la identificación de las aves de Argentina y Uruguay. Buenos Aires: Vazquez Mazzini.

Nogué, J. (Ed.). (2011). Paisatge i educación. Olot, España: Observatorio del Paisaje de Cataluña.

Rapoport, A. (1978). Aspectos humanos de la forma urbana. Barcelona: G.Gili.

Sala, P. (2013). Cartografiar els paisatges d avui i els que vénen. En J. Nogué (Ed.). Reptes en la cartografia del piasatge (pp.14-41). Olot, España: Observatorio del Paisaje de Cataluña.

Tuan, Y. (1990). Topophilia: a Study of Environmental Perception Attitudes and Values. New York: Columbia University Press. 